\title{
OPERATIONAL AND TECHNOLOGICAL PROPERTIES OF PLOUGHING BLOCK- MODULAR MACHINE-AND-TRACTOR AGGREGATE
}

\author{
Volodymyr Bulgakov ${ }^{1}$, Volodymyr Kuvachov ${ }^{2}$, Semjons Ivanovs ${ }^{3}$, \\ Viktor Melnyk ${ }^{4}$, Francesco Santoro ${ }^{5}$, Juri Olt $^{6}$ \\ ${ }^{1}$ National University of Life and Environmental Sciences of Ukraine, Ukraine; \\ ${ }^{2}$ Tavria State Agrotechnological University, Ukraine; \\ ${ }^{3}$ Latvia University of Life Sciences and Technologies, Latvia; \\ ${ }^{4}$ Kharkiv Petro Vasylenko National Technical University of Agriculture, Ukraine; \\ ${ }^{5}$ University of Bari Aldo Moro, Italy; ${ }^{6}$ Estonian University of Life Sciences, Estonia \\ semjons@apollo.lv, viktor_melnik@ukr.net,francesco.santoro@uniba.it, jyri.olt@emu.ee
}

\begin{abstract}
One of the topical directions in the development of agricultural tractor construction can be the formation of machine-and-tractor units according to a modular principle, using technological modules with the driving wheels. The aim of this work is to study the possibilities how to increase the operational and technological indicators of the operation of an agricultural aggregate in a modular aggregation system due to the selection of rational parameters of an elastic-dissipative connection of the energy and the technological modules. The obtained data were processed by statistical methods on a PC, using correlation and dispersion analyses. It has been established by experimental investigation that the operation of a ploughing block-modular aggregate, while ensuring rational rigidity of the connection of its energy and technological modules, is achieved by throttling the hydraulic system of its rear suspension at the level of $75 \%$, characterised by an increase in its performance by $6 \%$ and a decrease in the specific fuel consumption by $12.4 \%$. In addition, the level of vertical vibration load of the operator corresponds to the allowed fatigue rate for $8 \mathrm{~h}$ of work.
\end{abstract}

Keywords: block-modular aggregate, ploughing, efficiency, fuel, consumption.

\section{Introduction}

Despite the constant improvement and increase in the engine power, the classic scheme of tractors, used in agriculture, has several shortcomings $[1 ; 2]$. The alternative direction in the development of the tractor construction, which is the replacement with a tractor of the traction-energy concept of the drafttractor increasing its energy saturation and creation of the draft machine and tractor aggregates on its basis, has not yet been sufficiently studied. Of particular interest is the formation of agricultural aggregates on a modular basis, using technological modules with the driving wheels [3;4].

The built-in reserve of the engine power, which cannot be used through the undercarriage of the energy-saturated tractor-tractor, is carried out through the driving wheels of the technological module, when the modular system is used for aggregation, due to the adhesion weight, and not only of the weight of the tractor, but also the weight of the entire aggregate, including its technological part. Continuous fluctuations of the external load under the conditions of real operation of the agricultural block-modular aggregate lead to a decrease in the installed engine power and an increase in the specific fuel consumption per unit of the work performed [5;6]. A positive side effect of the technological module is damping of the oscillations, created by the resistance force of the agricultural implement. Damping of oscillations is carried out by elasticity of the pneumatic tires of the driving wheels and the inertia of the mass of the technological module. The study of the elastic damping properties of the technological module is of certain interest because they can significantly increase the smoothness of the block-modular aggregate and the operational and technological indicators of its operation. The efficiency of the work and use of the modular agricultural aggregates is determined, first of all by their correct completing, the choice of appropriate modes and the use of rational methods of work. As a result, this allows to gain maximum efficiency and minimum costs per unit of resources with maximum quality indicators of technological operations. The theoretical and practical aspects of using block-modular agricultural aggregates in the technological options have already been sufficiently studied [3-6; 8; 9]. According to the research results, constructive and technological schemes of the block-modular agricultural aggregates have been substantiated. The connection of the technological module with the power module is made using the rear hydraulic suspension mechanism of the latter. In addition, the hydraulic control valve spool of the hydraulic system of the power module is in a floating position. In this case, with forward vertical displacements of both modules, the flow of the hydraulic fluid from one cavity of the main hydraulic cylinder to the other occurs with the least dissipation of energy. Since the range of 
operating conditions of the block-modular agricultural aggregates is quite wide, and the irregularities of the agricultural backgrounds are characterised by a large number of disturbances, this negatively affects the smoothness of its movement [5]. Analysis of the smoothness of movement of the block-modular aggregates was treated in sufficient detail in the works by many researchers [4-11]. At the same time, the number of technological modules varied from one to three. There were attempts to introduce a hydraulic damper connection between two technological modules and the power module of the blockmodular agricultural aggregate in a horizontal plane [6]. A similar solution was used to reduce mutual oscillations of the energy and technological modules in the longitudinal-vertical plane [10]. As a result of the research performed by the scientists, it was found that the rational rigidity of the connection of the two modules in the aggregate is achieved by throttling the rear suspension mechanism of the energy module by the hydraulic systems at the level of 70-78\% [10]. However, the results obtained by the predecessors do not allow evaluating the efficiency of this method of increasing the smoothness of movement of the block-modular agricultural aggregates. Because of that it became necessary to conduct scientific research aimed at solving this problem.

The aim of the work is to study the possibilities of increasing the operational and technological indicators of the operation of an agricultural aggregate with a modular aggregation system due to the selection of rational parameters of the elastic-dissipative connection of the energy and technological modules.

\section{Materials and methods}

Experimental investigations conducted under the field conditions were based on both generally accepted standard and developed original methods, using special equipment with an ability to directly record the recorded signals on a PC [13]. The obtained data were processed by statistical methods on a PC using the correlation and variance analyses [14; 15].

A ploughing machine-and-tractor aggregate, based on a block-modular power facility, containing an energy module (MTZ-82 tractor), a technological module of our design, and a PLN-5-35 suspension plough was taken as a physical object of the research (Fig. 1). The undercarriage of the technological module is articulated. Its frontal rotary part is connected to the rods of the rear suspension of the energy module. A matching gearbox is installed on the rotary part of the frame, which synchronises the angular speed of the driving wheels of the energy and technological modules. The articulated design of the undercarriage of the technological module provides mutual turning of its frontal and rear parts in a horizontal plane by an angle of $\pm 30^{\circ}$ in both directions, and by an angle of $\pm 15^{\circ}$ in the transversely vertical plane when copying the irregularities of the field agrophone.

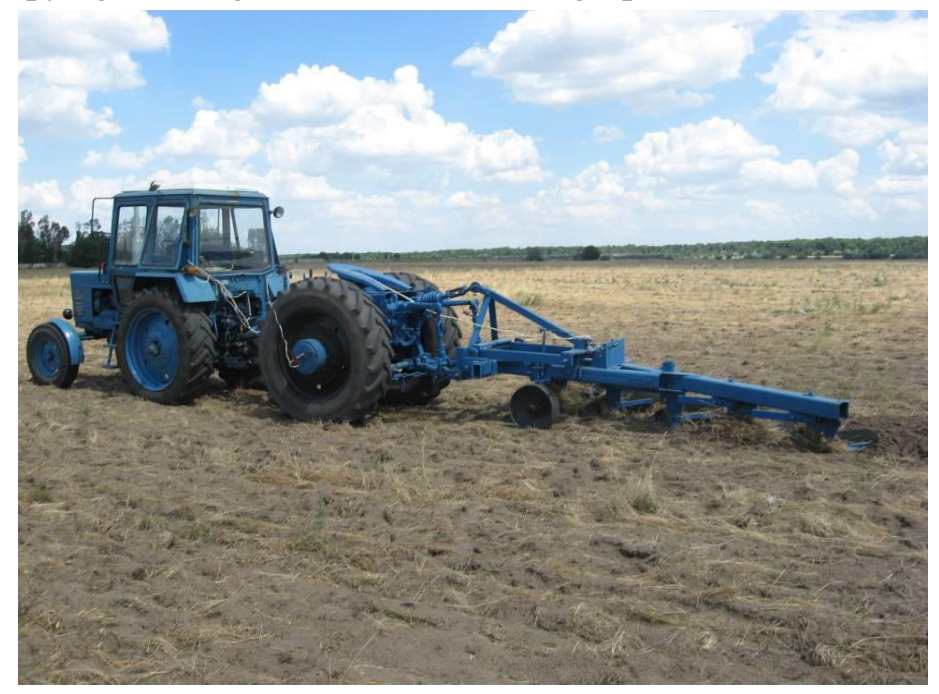

Fig. 1. Block-modular ploughing aggregate during the field experimental research

The operational and technological indicators of the ploughing block-modular agricultural aggregate were determined for two options for adjusting the rear suspension mechanism of its energy module. According to the first option, the hydraulic system of its rear suspension was in a floating position. According to the second option, a throttle was introduced into one of the hydraulic lines of the hydraulic system (Fig. 2), the degree of throttling of the hydraulic system being set at $78 \%$. 


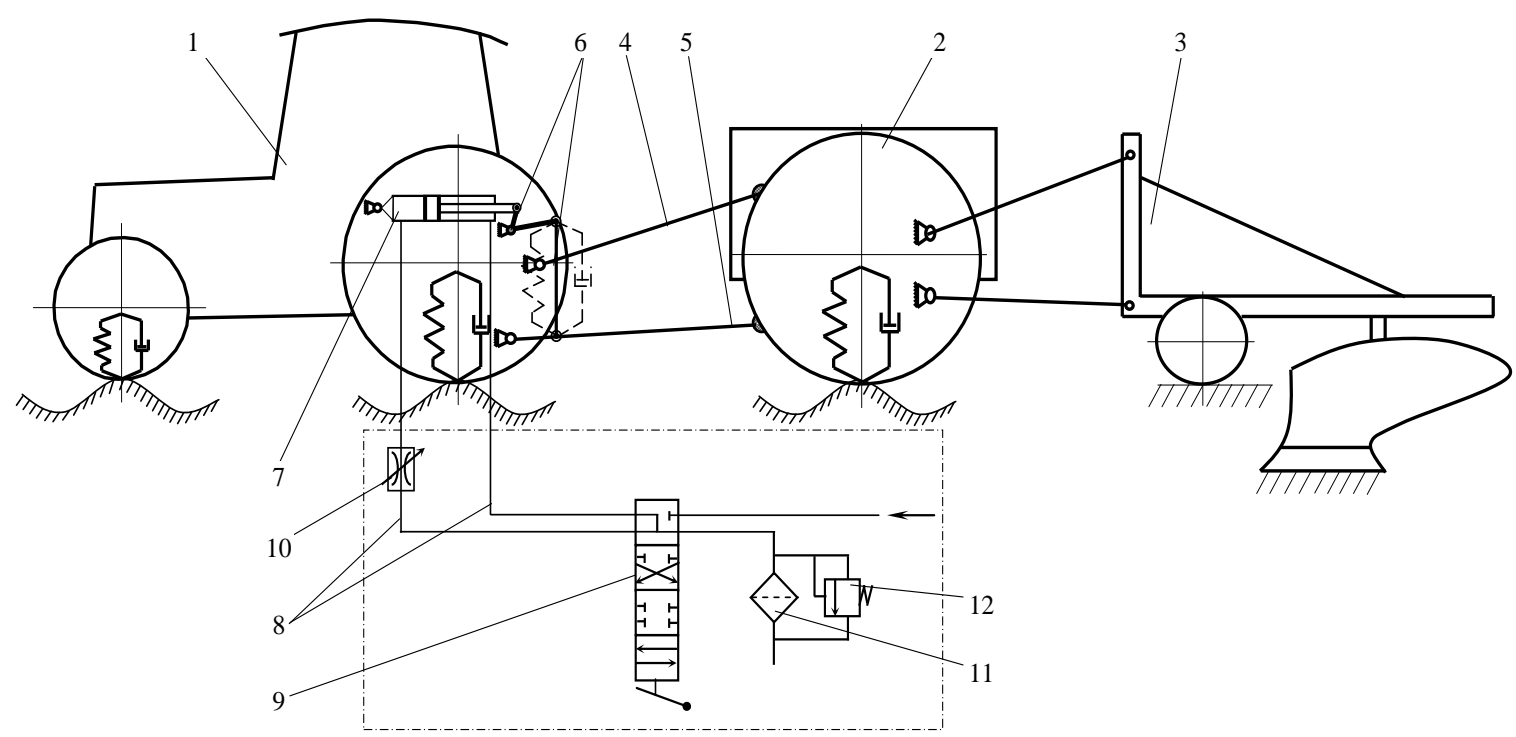

Fig. 2. Scheme of throttling of the hydraulic system of the rear suspension mechanism of the energy module: 1 - energy module; 2 - technological module; 3 - backflow preventer valve; 4 -central drawbar; 5 - lower links; 6 - levers and braces of the suspension mechanism; 7 - main hydraulic cylinder; 8 - hydraulic lines; 9 - hydraulic valve; 10 - throttle; 11 - filter; 12 - backflow preventer valve

Throttling of the hydraulic system of the rear suspension mechanism of the energy module was created by its elastic-dissipative connection with the technological module. The inertia of its mass makes it possible to reduce the intensity of mutual vertical oscillations of the two modules of the block-modular agricultural aggregate.

To determine the element-by-element time consumption during the operational and technological assessment of the operation of the ploughing block-modular aggregate, the methodology laid out in the Standard GOST 24055 "Methods of operational and technological assessment" was used. The basic indicator here is the time of the main operation of the $T_{1}$ aggregate. To calculate it, the following generalised formula is proposed:

$$
T_{1}=\frac{T_{n}-T_{311} / K_{m}-T_{322}-T_{5}-T_{61}-T_{71}}{1+\tau_{2}+\tau_{321}+\tau_{33}+\tau_{41}+2 \cdot \tau_{62}},
$$

where $T_{n}$ - standard duration of the shift, h;

$T_{311}$ - time spent for daily maintenance of the aggregate, $\mathrm{h}$;

$T_{321}$ - average duration of the transfer of the aggregate from transport to working position, and vice versa, $\mathrm{h}$;

$K_{m}-$ shift factor of the aggregate;

$T_{322}$ - time spent for the aggregation of the plough, h;

$T_{5}$ - time spent for rest of the operator, h;

$T_{6}$ - time spent on idle moving of the aggregate, $\mathrm{h}$;

$T_{71}-$ time spent for daily maintenance, $\mathrm{h}$;

$\tau_{2}$ - specific costs of the auxiliary time;

$\tau_{321}$ - specific time spent on transferring the aggregate from transport to working position, and vice versa;

$\tau_{33}$ - specific time, spent for debugging and regulation of the ploughing aggregate;

$\tau_{41}$ - specific time, spent for the elimination of technological failures;

$\tau_{62}-$ specific time, spent on moving from field to field.

To register the vertical accelerations $\ddot{Z}\left(\mathrm{~m} \cdot \mathrm{s}^{-2}\right)$ of the frame of a block-modular agricultural machine-and-tractor aggregate in the process of its movement during the experimental field studies, we used a tablet computer with the Android operating system. In this software environment, using a special 
application Accelerometer Meter (Version 1.32), digitised output signals and their frequency spectrum from the accelerometer sensors, built into the tablet computer, were recorded in time (Fig. 3).

a)

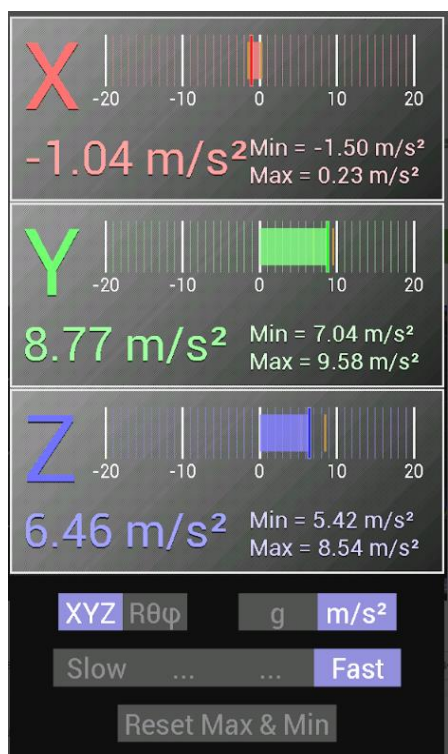

c)

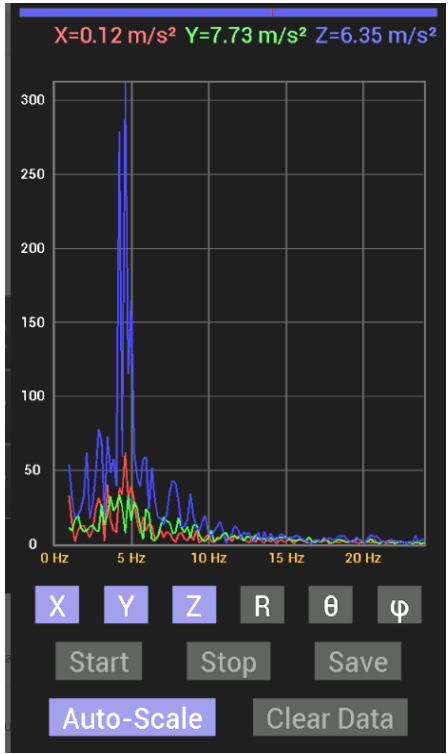

b)

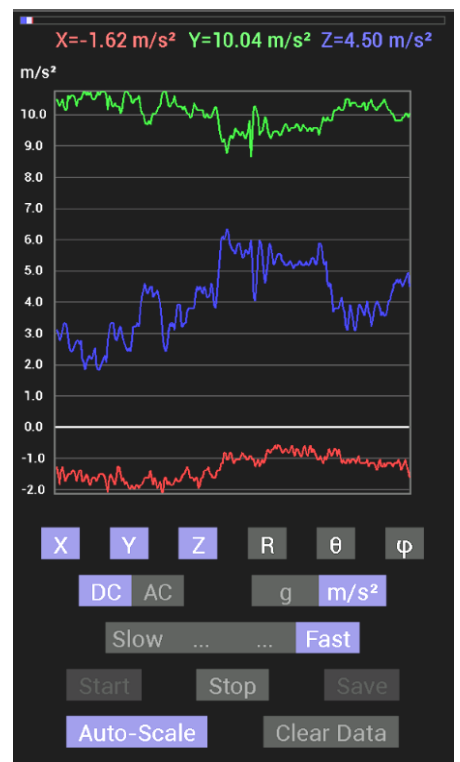

d)

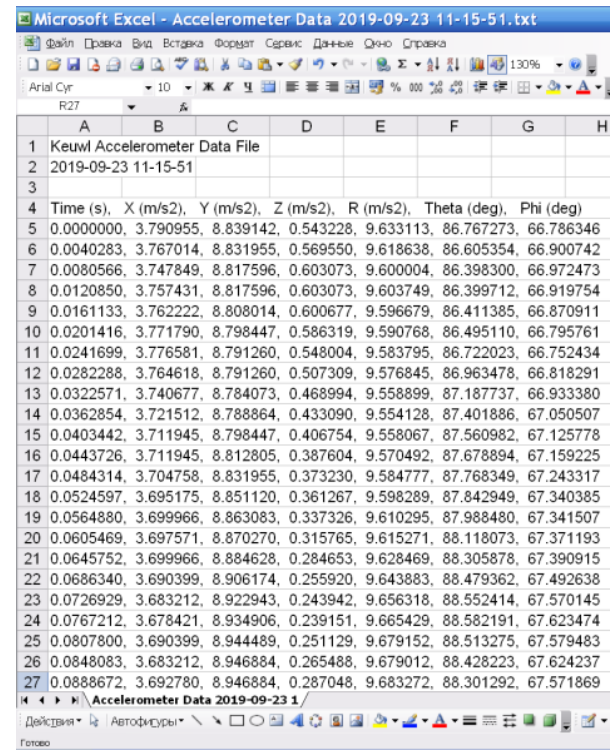

Fig. 3. Interface of the software environment Accelerometer Meter, based on Android:

$\mathrm{a}$ - registration of the vertical acceleration (marked by $\mathrm{Z}$ ); $\mathrm{b}$ - function of the recording measurement of the output parameters; $\mathrm{c}$ - frequency distribution of the amplitudes of the output parameters; $\mathrm{d}$ - results, exported into format ".txt"

The obtained digitised signals from the accelerometer sensors of the tablet computer (Fig. $3 \mathrm{~d}$ ) were imported into the Mathcad software environment to determine their statistical characteristics.

The experimental amplitude-frequency characteristic of the vertical oscillations of the blockmodular agricultural aggregate was found by the following expression:

$$
\grave{A}(\omega)=\frac{\sigma_{m}}{\sigma_{h}} \cdot\left(\frac{S_{m}(\omega)}{S_{h}(\omega)}\right)^{\frac{1}{2}},
$$


where $S_{h}(\omega)$ - spectral density of irregularities of the longitudinal profile of the agricultural background;

$S_{m}(\omega)$ - spectral density of acceleration of the vertical oscillations of the modular agricultural aggregate;

$\sigma_{h}^{2}, \sigma_{m}^{2}$-root-mean-square deviations of the irregularities of the profile of the agricultural background and the spectral density of the accelerations of the vertical oscillations of the modular agricultural aggregate.

The dispersions of characteristics of random processes at the output of the linear dynamic system were determined using the following dependence:

$$
D=\int_{\omega_{0}}^{\omega_{1}}|\grave{A}(\omega)|^{2} S_{h}(\omega) d \omega=\int_{\omega_{0}}^{\omega_{1}} S_{m}(\omega) d \omega,
$$

where $\omega_{0}, \omega_{1}-$ initial value and the cutoff frequency of spectral density.

During the research, the average soil moisture in the $0-30 \mathrm{~cm}$ layer was $21.5 \%$. The soil density ranged from 1.31 to $1.43 \mathrm{~g} \cdot \mathrm{cm}^{-3}$. There were organized working plots of the field, where time-based observations of the operation of this aggregate were conducted. The PLN-5-35 plough in both variants of the machine settings was adjusted to the ploughing depth of $26 \mathrm{~cm}$. To exclude the influence of the subjective factor, the same operator worked in the research process.

\section{Results and discussion}

The results of the operational and technological experimental field studies showed that the operation of the ploughing block-modular agricultural aggregate with throttling of the hydraulic system of its rear suspension allows to increase the speed of the working movement by 6\% (Table 1). As a result, efficiency for 1 hour of the main time is also directly proportional to a $6 \%$ increase. This can be explained by the fact that with a strong intensity of vertical oscillations of the ploughing aggregate, the operator is forced to subjectively, on the basis of his own feeling, to reduce the intensity of the oscillations by reducing the speed of the movement. And vice versa, improving the smoothness of the movement of the aggregate contributes to an increase in the speed of the aggregate.

In addition to the increase in the efficiency of this ploughing-modular machine-and-tractor aggregate, the specific (per hectare) fuel consumption is decreased by an average of $12.4 \%$, when the hydraulic system of its rear suspension is throttled (Table 1).

The rest of the indicators are at a sufficiently high level. The fact of increasing the efficiency of the ploughing aggregate as a result of increasing its smoothness of movement can be explained as follows. First, this is due to an increase in the efficiency of the aggregate, and, second, it is caused by an improvement in the operating mode of the diesel engine of the energy unit, since it is known that the fuel consumption of the tractor diesel engine under the operating conditions is associated with the operation of the engine in a transient mode [11]. According to the scientific research [12], the impact of the unstable modes has been established upon the operation of the speed control and the fuel supply system, as well as on the economy and durability of the automotive engines. At the same time, as a result of an increase in the smoothness of the movement of the ploughing block-modular aggregate, there is observed a decrease in the dispersion of oscillations on the power take-off shaft of the power module. This fact should be interpreted as a decrease in the impact of the non-stationarity of the operating modes of the engine of the energy module due to the oscillations of the moment of resistance on its shaft. This really finds confirmation in the decrease of the hourly fuel consumption of the engine of the power module as a result of the increase in the smoothness of the movement of the block-modular aggregate (Table 1).

By the results of investigations it has been established that the practical implementation of the requirements for the vertical vibratory loading by the operator of the wheeled machines and the safety of his work is achieved by rational choice of the rigidity of the connection of the two modules of the block-modular ploughing aggregate. In addition, due to a decrease in the dispersion of vertical oscillations of the aggregate, the oscillation with frequencies of more than $2 \mathrm{~Hz}$ are eliminated. 
Operational and technological indicators of the block-modular agricultural aggregate

\begin{tabular}{|c|c|c|}
\hline \multirow{2}{*}{ Indicator } & \multicolumn{2}{|c|}{$\begin{array}{l}\text { Value of the indicator for the variant of setting } \\
\text { the hydraulic system of the tractor suspension }\end{array}$} \\
\hline & $\begin{array}{l}\text { without throttling the } \\
\text { hydraulic system }\end{array}$ & $\begin{array}{l}\text { with throttling } \\
\text { the hydraulic system }\end{array}$ \\
\hline $\begin{array}{l}\text { Working conditions: } \\
\quad \text { - working speed of the movement, } \mathrm{m} \cdot \mathrm{s}^{-1} \\
\quad \text { - ploughing depth, cm }\end{array}$ & $\begin{array}{l}1.66 \\
26.0\end{array}$ & $\begin{array}{l}1.76 \\
26.0\end{array}$ \\
\hline Ploughing area, ha & 10.2 & 10.6 \\
\hline $\begin{array}{l}\text { Efficiency of work, } \mathrm{kg} \cdot \mathrm{h}^{-1} \text { : } \\
\text { basic time } \\
\text { shift tiome }\end{array}$ & $\begin{array}{l}1.04 \\
0.87\end{array}$ & $\begin{array}{l}1.10 \\
0.92\end{array}$ \\
\hline Specific fuel consumption, $\mathrm{kg} \cdot \mathrm{ha}^{-1}$ & 17.83 & 15.62 \\
\hline $\begin{array}{l}\text { Operational and technological indicators: } \\
\text { - coefficient of the working passes } \\
\text { - technical and technological maintenance } \\
\text { - use of the shift time }\end{array}$ & $\begin{array}{c}0.927 \\
0.93 \\
0.83\end{array}$ & $\begin{array}{c}0.923 \\
0.93 \\
0.84\end{array}$ \\
\hline Uniformity of the ploughing depth, cm & \pm 2.1 & \pm 1.9 \\
\hline
\end{tabular}

With a decrease in the intensity of impact upon the operator's body, the labor productivity increases. As a result of rational throttling of the hydraulic system of the rear suspension of the energy module of the block-modular aggregate it possible to achieve an acceleration intensity of the vertical oscillations at the level of $1 \mathrm{~m} \cdot \mathrm{s}^{-2}$ (Fig. 4). This increases the allowed duration of the operator's work to a an allowed fatigue limit of up to $8 \mathrm{~h}$.

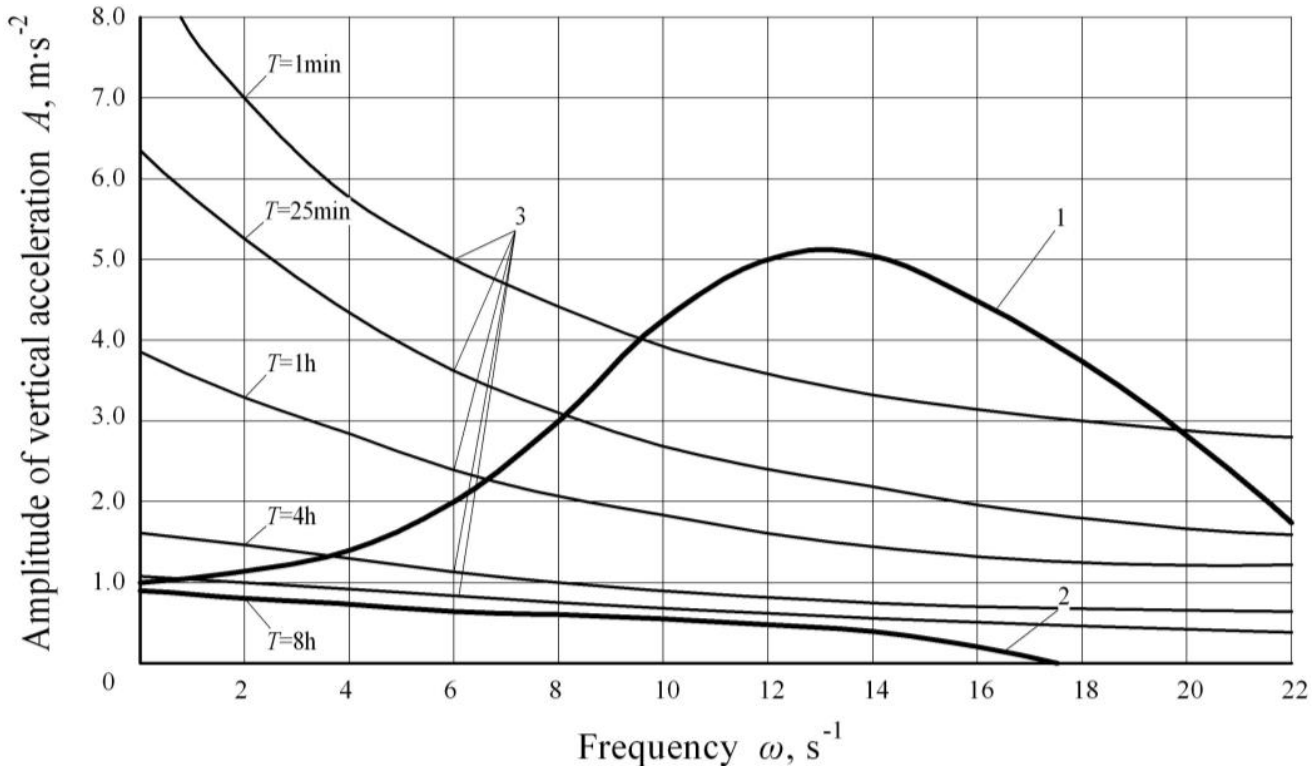

Fig. 4. Experimental amplitude-frequency characteristics of acceleration of the vertical oscillations of the frame of a block-modular aggregate when it reproduces oscillations of the track profile: 1 - without throttling the hydraulic system of the tractor; 2 - with throttling of the tractor hydraulic system at the level of 75\%; 3 - allowed duration $T$ of the operator's work until the level of his fatigue

The quality of ploughing in the compared variants of the ploughing block-modular aggregate was practically at the same level. With a confidence level of 95\% it can be argued that the differences between the average values of the surface ridge and the ploughing depth, as well as between the dispersions of these indicators, are purely random. The other operational and technological performance indicators are approximately the same. 


\section{Conclusions}

1. The operation of the arable block-modular aggregate, while ensuring the rational rigidity of the connection of its energy and technological modules, is achieved by throttling the hydraulic system of its rear suspension at the level of $75 \%$ and is characterised by the best operational and technological indicators. In particular, there is a $6 \%$ increase in the efficiency of the aggregate, and a $12.4 \%$ decrease in the specific fuel consumption.

2. With a decrease in the dispersion of the vertical oscillations of the ploughing block-modular aggregate, oscillations with frequencies of more than $2 \mathrm{~Hz}$ are eliminated. As their intensity decreases, the impact on the operator's body is weakened and the labour productivity increases. As a result of rational throttling of the hydraulic system of the rear suspension of the energy module of the block-modular aggregate, the acceleration intensity of its vertical oscillations decreases to $1 \mathrm{~m} \cdot \mathrm{s}^{-}$ ${ }^{2}$, which allows its operation up to $8 \mathrm{~h}$ at an acceptable level of fatigue.

3. The work of a ploughing block-modular aggregate, in which the energy and the technological modules are connected by a viscoelastic connection, makes no impact upon the quality of ploughing. With a confidence level of $95 \%$ it can be asserted that the differences between the mean values, as well as the dispersion of the ploughing quality indicators, are of a random nature.

\section{References}

[1] Viesturs D., Kopiks N. Trends in development of tractor fleet in Latvia. Engineering for rural development, 2017, Vol.16, pp. 534-539.

[2] Kopiks N., Viesturs D., Valainis O. The Fleet of Tractors on the Farms of Latvia, Its Structure and Energy Intensity. Engineering for Rural Development, Volume 14, 2015, pp. 84-87.

[3] Nadykto V. Modular energy units. The Ukrainian Farmer. No 7, 2010. pp.70-71. (In Ukrainian).

[4] Nadykto V. The role of modular power units in the formation of the type of tractors in Ukraine. Tractors and agricultural machinery. No 6, 2010, pp. 22-25. (In Russian).

[5] Ivanovs S., Bulgakov V., Nadykto V., Ihnatiev Ye., Smolinskyi S., Z. Kiernicki. Experimental study of the movement controllability of a machine-and-tractor aggregate of the modular type. INMATEH - Agricultural Engineering. 2020, Vol. 61 (2), pp. 9-16.

[6] Bulgakov V., Pascuzzi S., Beloev H, Ivanovs S. Theoretical investigations of the headland turning agility of a trailed asymmetric implement-and-tractor aggregate. Agriculture. Vol. 9(10), 2019, article 224

[7] Bulgakov V., Parakhin O., Mitkov V. The coefficient determination of a damperwasher hydraulic resistance for reducing a technical module oscillation amplitude. Modern Development Paths of Agricultural Production: Trends and Innovations Vol.1, 2019 pp. 183-190

[8] Nadykto, V., Kyurchev, V., Chaplinskyi, A. Ways to increase the traction efficiency of modular draft device. IOP Conference Series: Materials Science and Engineering, Volume 1021, Issue 1, 2021, Art. 012043.

[9] Belyaev N. Powerful and heavy-duty wheeled agricultural tractors abroad. Tractors and agricultural machinery. No 5, 1986, pp. 52-58. (In Russian).

[10] Kuvachov V., Katyukha D. Trends in the development of robust ownership of block-modular units. Journal TSATU. Vol.9 (3), 2009, pp. 82-86. (In Ukrainian).

[11] Antipin V.P. Determination of the influence of engine characteristics on its efficiency in unsteady mode. Dvigatelestroyeniye, No 8, 1981, pp.10-12 (In Russian).

[12] Antipin V.P. The nature of the influence of fuel consumption on the wear of the engine when operating in a transient mode. Dvigatelestroyeniye, No 3, 1987, pp.48-50 (In Russian).

[13] Доспехов Б. Методика полевого опыта (Methodology of field experiments). 2012. Moscow: Nauka, 352 pp. (In Russian)

[14] Ivanovs S., Adamovics A., Rucins A. Investigation of the technological spring harvesting variants of the industrial hemp stalk mass. Agronomy Research. Volume 13, Issue 1, 2015, pp. 53-60.

[15] Веденяпин С.В. Общая методика экспериментальных исследований и обработки опытных данных (General methodology of experimental research and processing of experimental data), Moscow, 1997, 159 p. (In Russian) 